\title{
ADVANCED DEMAND AND \\ A CRITICAL ANALYSIS OF REVENUE MANAGEMENT
}

IRENE C. L. NG ${ }^{1}$, Ph.D.

PUBLISHED IN THE SERVICE INDUSTRIES JOURNAL, VOL. 27, NO. 5, JULY 2007

${ }^{1}$ Irene C. L. Ng is with the Department of Management at the School of Business and Economics, University of Exeter, Honorary Professor of UTAR (Malaysia) and the Group Vice Chairman of the SA Tours Group (Asia). Correspondence address: School of Business and Economics, University of Exeter, Streatham Court, Rennes Drive, Exeter EX4 4PU, United Kingdom Tel: +44 (0) 1392 263250, Fax: +44 (0) 1392 263242, Email: irene.ng@exeter.ac.uk

Ng, Irene C.L. (2007), "Advanced Demand and a Critical Analysis of Revenue Management", Service Industries Journal, Vol. 27, No. 5, July 2007 


\section{ADVANCED DEMAND AND \\ A CRITICAL ANALYSIS OF REVENUE MANAGEMENT}

This paper presents a theoretical framework of advanced demand through six propositions. The framework introduces the concept of acquisition and valuation risks and suggests that advanced demand distribution is rooted in the trade off between them. Furthermore, since advanced buyers may not consume, firms may be able to re-sell capacity relinquished. The study then proposes how refunds could provide additional revenue to firms.

The study further suggests theoretical reasons why and when service firms are able to practice revenue management, suggesting that RM tools such as overbooking and demand forecasting may not be the only tools for higher revenue.

Keywords: Revenue Management, Advanced Selling, Risk, State dependent, Pricing

\section{INTRODUCTION}

Revenue management is the practice of obtaining the highest possible revenue in the selling of a service firm's capacity. Practitioners of revenue management use tools such as targeted pricing, market segmentation and demand forecasting so that the limited capacity of the firm is sold at the highest possible price. Since many customers buy in advance, the firm sets prices based on forecasted patterns of demand so that capacity sold to earlier (and perhaps lower paying) customers would not deprive the firm of obtaining higher revenue from customers arriving later. This practice is starting to find favor with many service firms that face relatively fixed capacity e.g. restaurants, hotels, cruise lines, electric power supply, and railways [Bitran and Caldentey, 2003]. Over time, revenue management has developed into a sophisticated practice as researchers use complex mathematical algorithms, coupled with technology, to allocate capacity, set prices and/or forecast demand.

Amongst revenue management researchers, there are differences in opinion about the scope of revenue management [Jones, 1999; Weatherford and Bodily, 1992]. Where revenue management is about algorithms and processes, operations research would dominate, as it has done so from the beginning. However, the scope of revenue management has expanded in the last ten years largely due to technological advances [Boyd, 2004]. Early streams tended to take prices as given and focused on optimization methods. As research in revenue management progressed, this approach was generally regarded as being too narrow [ $\mathrm{Ng}, 2004$; Talluri and van Ryzin, 2004; Weatherford, 1997] and price should be a decision variable in good revenue management practice. Moreover, the early researchers assumed that demand was independent and separable. Research has since then suggested that the firm's strategies could have an impact on demand, i.e. the multiple prices across differentiated services could influence consumers choices, and that could, in turn, influence quantities [Botimer and Belobaba, 1999; Weatherford 1997]. With greater emphasis on pricing and demand behavior, other models have emerged in marketing and economics (e.g. Png, 1989; Xie and Shugan, 2001; Shugan and Xie, 2000). Yet, there seem to be a lack of synthesis between the two streams, nor has there been any attempt to reconcile their apparent divergent emphasis. Advanced pricing models such as those described often dealt with individual consumer behavior or homogenous consumer

Ng, Irene C.L. (2007), "Advanced Demand and a Critical Analysis of Revenue Management", Service Industries Journal, Vol. 27, No. 5 , July 2007 
segments whilst revenue management researchers dealt with stochastic heterogeneous market demand.

With service firms operating in a more dynamic environment and with a broader scope placed on revenue management, there is therefore a need for a conceptual understanding of advanced demand. To that end, this paper aims to develop a framework that would lead to a proposed theory of advanced demand. The analysis show how research in revenue management can be integrated with pricing based on deterministic demand that is rooted on the fundamental behavior of consumers.

The framework presented proposes that advanced demand may not be as random as revenue management researchers have historically set it out to be. Due to the risk of not attaining a service at the time of consumption (i.e. acquisition risk), buyers are willing to purchase in advance. Yet, advanced purchase implies that the buyer may not be able to consume the service at the designated future consumption time because the utility derived from consumption is state dependent. This results in buyers facing a risk of low valuation (i.e. valuation risk), causing them to buy closer to consumption. The framework proposes that the distribution of advanced demand is a manifestation of the trade offs between acquisition and valuation risk faced by buyers. This trade-off also interacts with the firm's pricing policy in the sense that buyers may decide to buy early or later depending on the firm's advanced and consumption-time prices. Furthermore, since advanced buyers may not consume, firms may be able to re-sell capacity relinquished. Accordingly, advanced buyers may be preferred due to this characteristic. By extending the framework, the study then analyses the prospects of refunding advanced buyers who may not be able to consume and proposes 4 ways through which refunds could provide additional revenue to firms.

Through the application of the framework into other services, the paper suggests theoretical reasons why and when service firms are able to practice revenue management. This is because revenue management practice requires the existence of a meaningful selling period in advance, and this could only be so when acquisition risks are high. The investigation then critically analyses revenue management practices and tools such as overbooking and demand forecasting and suggests that they may not be the only tools on hand to obtain optimal revenue. The study proposes that a more satisfying approach might be to understand underlying advanced demand behavior so that firms do not merely accept the nature of advanced demand but could, instead, use acquisition and valuation risks as strategic levers to influence it.

The paper starts with a review of revenue management literature. The theoretical framework for understanding advanced demand is presented, together with six research propositions. Following on, the framework is applied into various services, to provide insights into why and how revenue management could be practiced across other services, and two corollaries are presented. A critique of revenue management practices and tools follows. Finally, the paper concludes with a discussion and some concluding remarks.

\section{THE EVOLUTION AND SCOPE OF REVENUE MANAGEMENT}

One of the most cited definition of revenue management is one that has been taken from American Airlines, which is to maximize revenue by 'selling the right seats to the right customer at the right tim', [1987, as cited in Weatherford and Bodily, 1992: 832] although this definition was subsequently modified to include 'and at the right price' [Kimes, 1989; Pak and Piersma, 2002; Kimes and Thompson, 2004; Yeoman et al., 1999; Upchurch et al., 2002]. While this might seem to be broad enough to encompass everything, it is not scientifically useful as what is

Ng, Irene C.L. (2007), "Advanced Demand and a Critical Analysis of Revenue Management", Service Industries Journal, Vol. 27, No. 5 , July 2007 
right in one regard may not be right in another. Furthermore, such a definition poses serious ontological difficulties. Hence, despite its widespread use, other researchers have asserted that there is no satisfactory definition of revenue management that represents the standard in literature (e.g. Jones, 1999; Weatherford and Bodily, 1992).

There are a few reasons for this. It has been acknowledged that revenue management research has evolved over the past 30 years and its definition has similarly evolved [Kuhlmann, 2004]. In addition, depending on the focus of a particular revenue management paper, the definitions would either widen or limit the scope of revenue management. Finally, many of revenue management tools and practices have been incorporated into the actual definition itself. The first two reasons will be examined further below while the third reason will be examined in later in the paper.

Revenue management started in the seventies with Rothstein [1971, 1974] and Littlewood [1972], where they investigate practices of revenue management in airlines and hotels. When the airline industry was deregulated in 1978, interest in the topic strengthened, as many airlines reported increases in revenue of $5 \%$ or more after starting a revenue management program [Kimes, 1989]. This led to the seminal papers of Belobaba [1987a, b, 1989] that served to propel revenue management into mainstream operations research (OR). However, the understanding of revenue management then was largely on a computational and operational level with literature dominated by operations researchers [Desiraju and Shugan, 1999]. Hence, the scope of revenue management was limited to capacity planning and allocation, for a given set of pricesii.

The problem with the original OR-centered approach was that an exogenous demand profile where the profile was divorced from both the capacity allocation and pricing decision of the firm was fallacious [Ng, 2004; Talluri and van Ryzin, 2004; Weatherford, 1997]. When a firm changes the capacity allocated to a particular price level, the firm should optimally revise its pricing policies. In turn, demand conditions would similarly adjust. Consequently, revenue management research was pressured to bring in the pricing policies of firms, and also to make demand or consumer behavior endogenous to revenue management [Fleischmann et al., 2004]. It also became clear that the revenue management practice was applicable to other service firms besides airlines and hotels. This led to more research papers on its practices in other industries such as car rental and Internet service providers (e.g. Carroll and Grimes, 1995; Nair and Bapna, 2001). By applying such practices to other firms, it became apparent that revenue management practices had to deal with prices that, again, may not be separable (c.f. Weatherford 1997).

Revenue management also became increasingly complex due to the advent of the Internet and other advances in technology [Elmaghraby and Keskinocak, 2003]. There were great leaps in computation power, allowing for more complex optimizing algorithms to emerge. Additionally, the Internet allowed for data to be collected constantly, feeding the algorithms with much needed fodder to generate better forecasts to aid firms in both capacity allocation and pricing. This resulted in the possibility of instantaneous decision making, allowing revenue management systems to be more efficient and responsive. As the Internet became ubiquitous, the information asymmetry between supply and demand reduced. Previously, demand data was far more difficult to obtain and less systematic to process. Consequently, supply-driven revenue management was a natural research orientation. With more demand data being made available, a balanced view of revenue management became necessary, and is perceived to have increasing research possibilities.

As the scope of revenue management started to expand beyond being an optimization issue to include pricing and demand behavior, revenue management became multi-disciplinary

Ng, Irene C.L. (2007), "Advanced Demand and a Critical Analysis of Revenue Management", Service Industries Journal, Vol. 27, No. 5 , July 2007 
in nature with pricing/demand and consumer research as one stream of focus and capacity allocation, booking policies and related supply-driven issues as the other [Kimes, 2003].

However, even without revenue management, pricing has already attracted considerable research interest, particularly in the area of dynamic pricing, where prices could be changed quickly, and with ease, on the Internet [Elmaghraby and Keskinocak, 2003]. A review on the practices of dynamic pricing with revenue management was presented by Elmaghraby and Keskinocak [2003], whilst a review of dynamic pricing, and its implications for consumer behavior, can be viewed at Kannan and Kopalle [2001]. .

Researchers realized that the revenue management problem was not adequately dealt with within just one discipline. Pricing and demand behavior were important, but then so was capacity allocation and planning, and both needed to be brought into revenue management. Despite the need for integration, there were few who attempted it [Fleischmann et al., 2004; Kimes and Wirtz, 2002, 2003]. This is also reflected in practice whereby, in commenting on the airline industry, Cary [2004: 202] claimed:

\section{...Pricing and revenue management - function so differently within the US airline industry. Pricing is almost entirely outwardly focused on the actions and reactions of competitors. Revenue management is almost entirely inwardly focused on the patterns and trends in historical demand data. Both are in need of adjustment.}

Seen from a political angle, it is commonly believed that the power for disciplines often comes from control over ideas [Martin, 1998]. Consequently, contribution to revenue management knowledge depended on how the revenue management problem was described. OR-centered revenue management problems dealt primarily with supply issues of overbooking, capacity allocation and demand forecasting (e.g. Pak and Piersma, 2002). For example, as recent as 2004, Gorin and Belobaba's [2004: 216] definition of revenue management within an airline industry was 'the combination of forecasting and optimization algorithms which enables the airline to maximize revenues, given a set of fares, by determining how much seat inventory to make available to specific fare products based on forecasts of expected demand for each fare product'. In contrast, other disciplines framed the revenue management problem to deal with maximizing profit through pricing or consumer choice models (e.g. Lee and $\mathrm{Ng}, 2001$; Elmaghraby and Keskinocak, 2003; Talluri and van Ryzin, 2004; Subramanian et al., 1999; Bertsimas and Perakis, 2001). For example, Subramanian et al. [1999: 147] defined revenue management as 'a commodity or service (such as the use of a hotel room on a particular date) that is priced differently depending on various restrictions on booking (e.g. advance purchase requirements) or cancellation (e.g. nonrefundability or partial refundability)'.

Since definitions are often more exclusive than inclusive, the definition of revenue management tended to indicate which domain is in control of knowledge within that topic. In the early days of revenue management research, the definition of revenue management was clearly accepted as one that was firmly entrenched in the OR domain [Williams, 1999]. Even up to 1999, in the editorial introduction to Yield Management for the Journal of the Operational Research Society, Yeoman et al. [1999: page 1083] claimed that a commonly recognized broad definition of $\mathrm{YM}$ as 'the process of allocating the right capacity or inventory unit to the right customer at the right price so as to maximize revenue or yield'. Similarly, Desiraju and Shugan's paper in the 'Journal of Marketing' [1999] compared strategic service pricing with yield management, taking them as two disparate practices. In recent years, pricing and demand behavior have been brought into revenue management researchiii (e.g. Feng and Gallego, 2000; Radjou et al., 2003] and the lack of a standard definition of revenue management claimed by 
Jones [1999] served to demonstrate the tension between the disciplines researching in the area. Notwithstanding the influences from other disciplines, the literature in revenue management is still heavily dominated by operations research. Although OR-researchers now acknowledge that demand and the consumer is endogenous to the revenue management problem [Boyd and Bilegan, 2003], definitions are still supply-centric as evidenced by the definition by Kimes and Thompson [2004, page 371]:

Revenue Management is a form of capacity management in which demand and supply are managed by manipulating length of usage and price (emphasis added)

This is in contrast to Fleischmann, Hall and Pyke [2004, page 9]:

Revenue Management ...is concerned with pricing a perishable resource in accordance with demand from multiple customer segments so as to maximize revenue or profit

One of the main difficulties in integrating pricing research with capacity allocations is that OR-based revenue management often assumed demand to be stochastic or probabilistic, whilst pricing research would tend towards modeling demand as deterministic. A stochastic or probabilistic demand seemed justified on the basis that consumers 'arrive' at random times before consumption. From the pricing perspective though, a theoretical structure was needed to explain how demand is shaped or why it would follow a particular pattern across time. Otherwise, there was no assurance that the past is able to predict the future [Bernstein, 1996; $\mathrm{Ng}, 2004]$. Accordingly, despite tremendous computing power available today, pricing based on demand forecasts faces the same old problem in conventional probability theory, where according to Bernstein [1996, page 334], 'the raw material of the model is the data of the past'.

Some research studies have attempted to shed some light on the behavior of the advanced buyer. The literature is scant, dominated by marketing literature, and not commonly brought into revenue management research. For example, Desiraju and Shugan [1999] evaluated strategic pricing in advanced selling and found that yield management strategies such as discounting, overbooking and limiting early sales work best when price insensitive customers buy later than price sensitive customers. Shugan and Xie [2000] showed that due to the state dependency of service utility, buyers are uncertain in advance and become certain at consumption time while sellers remain uncertain of buyer states at consumption time because of information asymmetry. They suggest that advance selling overcomes the informational disadvantage of sellers and it is therefore a strategy to increase profit. Xie and Shugan [2001] studied when advanced selling improves profits and how advanced prices should be set. They have also investigated the optimality of advanced selling, investigating selling in a variety of situations, buyer risk aversion, second period arrivals, limited capacity, yield management and other advanced selling issues.

Png [1989], on the other hand, showed that costless reservations in advance is a profitable pricing strategy as it induces truth revelation on the type of valuation that consumer has for the service (which is private information). If the consumer has a high valuation i.e. ability to consume, s/he will exercise the reservation and pay a higher price. If not, the consumer will not exercise. In another paper, Png [1991] compared the strategies of charging a lower price for advanced sales and attaching a price premium at the date of consumption versus charging them a premium and promising a refund to them should consumption prices be lower than what was purchased.

Despite these models that aim to capture primitive advanced demand behavior, there has not been much effort to integrate them into a unified framework nor have there been any attempt

Ng, Irene C.L. (2007), "Advanced Demand and a Critical Analysis of Revenue Management", Service Industries Journal, Vol. 27, No. 5 , July 2007 
to bridge the behavioral aspects of demand with revenue management research. Models of the former capture individual consumer behavior (or homogeneous consumer segments) and it was difficult to see how that could be aggregated and applied to revenue management that mostly dealt with stochastic heterogeneous market demand. Lee and $\mathrm{Ng}$ [2001] attempted to model the demand phenomenon at a market level but it was unclear why their demand function was shaped the way it was.

To that end, this paper aims to develop a framework that would lead to a proposed theory of advanced demand that will, in turn, facilitate future research in pricing and revenue management of services. This framework sets out its fundamental premise in the next section.

\section{THEORETICAL FRAMEWORK OF ADVANCED DEMAND}

One common thread that cuts across all research in revenue management is the element of purchase time. The revenue management problem has often been framed as whether to wait until close to perishability to take on customers willing to pay higher prices or to take earlier arrivals at a lower price. From a demand perspective, revenue management is essentially a price discrimination problem across time of purchase [Dana, 1999]. There are compelling reasons why revenue management has confined itself only to the time of purchase. Revenue management historically has been founded on revenues of perishable assets such as airline seats, hotel rooms, etc. and many researchers' definitions of revenue management presume time of purchase as the factor for discriminating revenues, whether through prices, or through capacity allocation [Elmaghraby and Keskinocak, 2003]. In establishing the framework for advanced demand, time of purchase is quintessentially relevant, as I will elaborate below.

Let us take, as an example of a perishable asset/service, pricing a room in a 300-room hotel on New Year's Eve. The room could be sold 6 months or probably even a year in advance. The mere fact that it can be sold in advance shows that there must be willingness on the part of the customer to buy before the day of consumption, factors that will be discussed in the framework below. For now, let us think about the value the customer attaches to the room in advance, and that the firm wishes to capture that value in the asking price of the room. This value would not only differ across different customers but even for just one customer, it would differ according to when he wishes to purchase it. If it is too far in advance, he might not even be willing to buy.

Let us label the time from when the room service holds some value to some customer somewhere all the way until its production/consumption on New Year's Eve as the service's selling period. Figure 1 illustrates a typical difference between a good and a service. Accordingly, the service can be sold at any time during its selling period. However, while it is sold at a different time, the very act of producing a service for a customer requires the source to be present, either as man or machine. This means that the production and consumption of a service is simultaneous, as it is widely established [Rathmell, 1966; Regan, 1963; Johnson, 1970; Bateson 1977]. Once the room is produced and consumed on New Year's Eve, it has perished and its selling period has ended. Since the service can only be sold during its selling period which ends at the production of the service, one can conclude that services can only be sold before production (and consumption, since both are simultaneously held). This is an important point because it alludes to a key difference between services and goods. Whilst goods can also be sold before production, the manufacturing firms retain a choice of whether to sell before or after production. This choice is not available to services.

Some may argue that certain services are actually produced in advance e.g. the production of a movie. Undeniably, the creation of a service may require its materials and 
equipment to be produced in advance such as a hotel building, aircraft or even telecommunication towers. Yet, the value of a service is only unlocked at the point when it is performed and consumed by the customer; the same value held by the customer that can be converted into revenue to the firm through the price the customer is willing to pay. In the case of the movie, the customer values the performance of the service by the firm (through the provision of the movie, comfortable seating, quiet surroundings, etc.), which is simultaneously consumed by him or her. Without the customer's consumption, which can only arise if the firm produces the service, the value of the service cannot be converted into revenue, despite the production of the necessary equipment.

It ought to be clearer now that the issue of pricing in service is therefore the issue of advanced pricing, even though the time in advance may be mere minutes, e.g. the purchase of a movie ticket just before the movie (c.f. Edgett and Parkinson, 1993).

Stylized Fact 1: The perishability and inseparability of services results in all sales of services to be advanced sales ${ }^{i v}$

Consequently, it is not unreasonable to assert that the perishability and inseparability of services results in the pricing of services as advanced pricing, i.e. revenue management is the management of advanced revenues. This implies that a firm must be able to command different pricing across the selling period of its service, and to do so, it must be able to sell far in advance. In other words, the ability of a firm to sell in advance is implicitly a pre-requisite in revenue management practice. Without it, the only revenues to manage are those contributed by customers buying at the point of consumption.

\section{Valuation risk compels buyers to buy close to consumption}

Since production and consumption are simultaneous, the consumer can only buy in advance and consume later without the chance to store. Similarly, the firm can only sell in advance and produce later. This is an important point. Conventional economic wisdom informs us that we buy only when the utility we attach to consuming the product outweighs the price we are supposed to pay for it. However, normative economics and marketing literature often implicitly assume that buyers receive utility at the time of purchase. Since there is now a separation of time between purchase and consumption, it implies that the consumer's utility is truly obtained not at the time of purchase, but at the point of consumption (c.f. Shugan and Xie, 2000). This is significant because when there is a separation of purchase and consumption, there is a probability that a buyer who has purchased may not be able to consume i.e. to use the term from economics - the utility becomes state dependent (c.f. Karni, 1983; Fishburn, 1974; Cook and Graham, 1977). Put simply, a buyer who buys a movie ticket an hour before the movie might find that $\mathrm{s} / \mathrm{he}$ is unable to watch the movie when the time comes because s/he has fallen ill. Hence, a key difference between a good and a pure service is that for goods, the consumer chooses the time (and the state) that is most suitable for consumption, after s/he has purchased the good e.g. taking a can of coke out of a fridge to drink it on a hot day, whilst in the service consumer, s/he needs to buy the service first and then consume it later, when its state is uncertain. The application of state dependent utility theory into service research was first proposed by Shugan and Xie [2000], when they investigated spot and advance pricing decisions and the optimality of advanced selling.

Note that the utility of the service buyer may not drop to zero. It might be that the state of the world has rendered the consumption of the service less valuable e.g. an open-air concert under the rain. Since the buyer faces uncertainty in ascertaining the value of the service at the time of consumption, s/he faces a risk, which this study terms as valuation risk. 
Research Proposition 1: $\quad$ Buyers facing high valuation risk would prefer to buy at the time of consumption

From the proposition above, it is logical that buyers will choose the time when it is most conducive for consumption and will turn up to buy seconds before consumption (commonly labeled as 'spot time').

\section{Acquisition risk compels buyers to buy in advance}

As many service firms operate with capacity constraints, buyers may not be able to obtain the service if they all show up at spot. Accordingly, if a buyer waits to buy only at spot time, he faces the uncertainty that the service may not be available. Even if there is capacity available, the firm may price higher at spot, thus rendering the service unattainable to some. I term this risk of not attaining a service as acquisition risk. To alleviate this risk, consumers may be willing to purchase further in advance of consumption, as insurance. Previous theoretical literature in advanced selling has claimed that advanced purchasing is common in many service industries for the reason of capacity limitation [Png, 1989; Lee and Ng, 2001; Shugan and Xie, 2000; Xie and Shugan, 2001]. Consequently, buyers who wish to be sure of obtaining a service may buy in advance.

Research Proposition 2: $\quad$ Buyers facing high acquisition risk would prefer to purchase in advance

A further anomalous aspect of services is that the value attached to the service by the consumer often includes the element of time, i.e. the service is valued at a particular time and that time element becomes an attribute of value to the consumer. Since time of consumption can never be perfectly substitutable, acquisition risk is heightened. This is clearly the case for many important events, e.g. weddings, where dates are booked well in advance.

Research Proposition 3: $\quad$ Acquisition risk is heightened when a specific time of consumption is an important attribute in the value of the service

Technically, the purchase further in advance and the purchase at spot are deemed as advanced purchases. However, for purpose of clarity, I term purchases close to consumption as spot purchases and purchases further in advance as advanced purchases, consistent with the terminology used by extant literature on this phenomenon. In reality, as elaborated by Lee and $\mathrm{Ng}$ [2001], the point where advanced purchase ends and spot purchase begins is industry specific and is also dependent on 'rate fences' erected by the seller [Lovelock and Wirtz, 2003]. Rate fences are constraints or conditions imposed by service firms to ensure minimal cannibalization of purchase. Consequently, the service industry is host to a wide range of advanced prices called 'forward prices, pre-paid vouchers, super saver prices, advance ticket prices, early discounted fares, early bird specials, early booking fares, and advance purchase commitments' [Xie and Shugan 2001, page 219].

Clearly, there is a trade off between the buyer's acquisition risk and valuation risk. Hence, there exists a market for selling the service far in advance for buyers who would like to ensure that the service is available, regardless of whether the seller is willing to sell to this market. Similarly, there also exists a market for selling at (close to) consumption time for buyers who would like to ensure that they are able to consume.

In practice, a service can face a heterogeneous market of buyers with both high valuation and acquisition risk. For example, a flight from London to New York will be a service with high

Ng, Irene C.L. (2007), "Advanced Demand and a Critical Analysis of Revenue Management", Service Industries Journal, Vol. 27, No. 5 , July 2007 
acquisition risk for a passenger that needs to get on a particular flight, e.g. to attend her/his son's graduation. S/He will therefore purchase in advance. If the price is too high, s/he will choose an alternative (perhaps another airline) and s/he may not risk waiting until spot, as s/he needs to be in New York at that particular date. In contrast, business executives who do not know when they may be called to go on business trips to New York will not be swayed to buy in advance, as they may be unsure of the traveling date.

Insert Figure 1 about here

As illustrated in Figure 1, the trade-off between acquisition risk (which drives consumers' willingness to buy further in advance) and valuation risk (which drives consumers' willingness to buy closer to consumption) means that the distribution of demand across the selling period of the service becomes important in the firm's pricing decision. In this respect, firms face uncertainty in demand distribution across time. For many revenue management consultants, accurate demand forecasting, coupled with dynamic optimization algorithms across time is key to better pricing decisions and improving profitability for service firms. Although some researchers have pointed out that demand forecasts should be adjusted when there are price changes (e.g. Talluri and van Ryzin, 2004), revenue management researchers in almost all instances have assumed advanced demand to be stochastic in nature, and/or the consumer choice behavior as probabilistic. Earlier in this paper, I stated that this assumption is justified on the basis that consumers 'arrive' at random times before consumption and this drives the belief that forecasts should aim for greater accuracy. As my analysis has shown, striving for greater forecast accuracy may be missing the point. There is a distinction to be made between buyers' discovery of their need for a service and when they choose to purchase, a distinction that traditional revenue management 'arrivals' do not take into account. In other words, 'arriving' may not always mean 'buying'.

Accordingly, as I have argued above, advanced demand may not be all stochastic in nature. There is an aspect of advanced demand where its antecedent lies in the trade offs between acquisition and valuation risks.

Research Proposition 4: $\quad$ The antecedents to the distribution of advanced demand across the selling period lie in the aggregate of consumers' individual tradeoffs between acquisition and valuation risks.

The revenue management/pricing problem does not end there. The firm's decision on price also has an effect on the buyers. For simplicity, it is assumed only two times exist in the service's selling period to sell - advanced time, denoting selling the service far in advance and spot time, denoting the selling of the service at a time closer to consumption. If the advanced price is low, the discount from spot price might outweigh the valuation risk faced by spot buyers. Likewise, if the spot price is low, advanced buyers might wait until spot to buy. Consequently, there is some degree of cross-time dependence between advanced and spot demand. Once this principle is extrapolated across multiple selling times in a service's selling period (i.e. beyond 2 times), the full extent of the firm's complex pricing decision can be appreciated. Moreover, what has been discussed is assuming that prices are segmented on time alone. Many services offer discriminatory prices across various service attributes or channels [Botimer and Belobaba, 1999; Weatherford, 1997]. When all these are considered, the demand behavior across time is even more confounding. 


\section{Re-selling capacity}

A crucial difference between pricing for services and goods is embedded in another effect of inseparability. Even if buyers are to buy in advance, advanced selling requires the buyers to still present themselves (or at least, the item that requires the service) at spot time. In other words, since services are inseparable in consumption and production, each advanced buyer has to 'show-up' to consume. Especially when the purchase is conditional upon a particular time of consumption, there will be a fraction of advanced buyers that may not be able to consume the service during that specified time. This is commonly acknowledged in various revenue management literatures, where attempts have been made to structure various reservation policies to minimize the impact of the cancellation and 'no-show' concept of advanced selling. (e.g. Alstrup et al., 1986; and Belobaba 1989; Hersh and Ladany, 1978; Subramanian et al., 1999; Toh, 1985). What has not been discussed is that the existence of a non-zero probability of non-consumption by advanced buyers provides a service firm with a unique opportunity not presented to goods firm i.e. the ability to sell the capacity that was already sold in advance - again at spot. This re-selling capability may then translate into additional profit for the firm either in the additional spot sales or overselling beyond the firm's capacity in advance. This point can be illustrated through two examples. First, tow truck services operate with limited capacity but sell (albeit at a very low price) through the Automobile Association (AA) an enormously large number of its services in advance, often through emergency services insurance. Since the fraction of the market that actually requires a tow truck service may be low, the firm obviously oversells its capacity in advance as well as re-sells it at spot (at a high price for those who did not subscribe to the insurance). Also, IT support services are usually oversold to buyers in advance since the fraction of non-consumption may be high, especially if the IT hardware and software is reliable and operates well.

Research Proposition 5: When advanced selling is possible (due to high acquisition risks), and ceteris paribus, advanced buyers are preferred because every advanced buyer provides the firm with a non-zero probability of being able to re-sell.

The ability of firms to re-sell relinquished capacity of advanced buyers can be executed in a few ways. First, the firm can re-sell to spot demand, if spot demand exists. Second, the firm could have inventoried advanced demand and re-sells the capacity to those on the 'waiting list'. Finally, the firm could try to forecast the proportion of non-consuming advanced buyers and oversell that proportion to advanced buyers. This final option is what is commonly referred to in revenue management as overbooking (e.g. Karaesmen and van Ryzin, 2004). Clearly, from the discussion above, overbooking is not as simple when viewed against the broader context of the phenomenon.

\section{Extending the Framework: Refunding advanced buyers}

Depending on the demand distribution across time, the level of non-consumption and capacity, firms might be prepared to manipulate advanced and spot prices to optimize profits. For example, if non-consumption is high and spot demand is strong, the firm may have an incentive to sell at discounted prices to advanced buyers because non-consumption allows the firm to earn additional re-selling revenue on top of the discounted prices. This may be a strategy firms could employ to stimulate demand particularly when competition is keen. Paradoxically, it may even be more profitable for the firm if advanced buyers do not show up. Consequently, there could be instances where the firm could provide partial or even full refund to advanced buyers should they be unable to consume. 
Providing refunds for buyer's inability to consume is widely practiced in the airline industry. Some tickets even provide a full refund to the customer. Generally, a full refund means that the ticket purchased can be returned to the airline for a complete reimbursement of the price at any time - even after the proposed date of travel. Furthermore, many airlines allow a refund on nonutilized sectors (e.g. if the consumer has purchased a return ticket but only utilized one leg of the ticket).

There is a fundamental difference between a full refund of this nature and those given out by retail shops for goods purchased. In the latter, the refund is given (or promised) if the firm fails the consumer i.e. the compensation is provided to the buyer due to firm's failure to deliver the benefits, according to the buyer's perception. In the former, and also the focal point of this study, refunds are promised for buyer failure i.e. the buyer's inability to consume.

Png's [1989] model attempted to shed some light on this phenomenon. While he found that firms' advance orders are not optimal, his study showed the profit maximizing strategy is to insure the risk adverse customers by compensating them when their valuation is low and charging then high when their valuation is high. However, this strategy requires the advanced buyer to face the risk of unavailable capacity at the time of consumption. In other words, Png's advanced buyer does not actually buy the service; he merely buys the option of purchasing the service at the time of consumption, at a stipulated price i.e. a price option. This is in contrast to the buyer failure refund of the type practiced by airlines where it is clear that the buyer buys with a firm advance order (i.e. capacity is guaranteed) with a refund in the event of a low valuation. Xie and Shugan [2001] showed that firm advanced orders with a refund offer may be optimal as the firm is able to obtain a higher price in advance to compensate for the cost of refund, as well as derive greater profits from cost savings in not having to serve these customers.

Within the framework presented above, I would agree with Png and Xie and Shugan that providing a refund is a useful strategy since high valuation risk buyers may be enticed to buy in advance, instead of seeking substitutes, and buyers may be prepared to pay higher for a refund offer. However, both models do not take into account the fact that a buyer who buys in advance has a non-zero probability of not consuming and that non-consumption frees up the capacity to be re-sold. Furthermore, consumers in aggregate form a heterogeneous market and demand dynamics may influence the premium for refund. Integrating these models into the current framework, the following proposition suggests how a refund offer can be integrated into conventional revenue management:

Research Proposition 6: $\quad$ Offering a refund to advanced buyers allow the firm to earn higher revenue from (a) extracting a higher price from advanced buyers and/or (b) the re-selling of capacity relinquished by advanced buyers, and/or (c) obtaining higher demand from the advanced market as a result of the refund offer and/or (d) keeping the portion of the price not refunded to buyers (for partial refunds)

By employing (a), buyers pay a higher price ex-ante (beforehand, i.e. before consumption). The firms obtain higher revenue because buyers are prepared to pay a premium for insurance against a low valuation, consistent with Png [1989] and Xie and Shugan [2001]. By employing (b), the same premium may be financed by the re-sale of relinquished capacity at spot, which may or may not lower advanced prices, depending on the price the firm is able to obtain. By employing (c), the premium could be financed by an expansion of demand due to the refund offer, and finally, by employing (d), the buyer pays a higher price ex-post (i.e. based on past event), when the state has become known. 
To elaborate on this proposition, consider an advanced return ticket that has been sold to a buyer at a higher fare, because a refund is offered, i.e. the firm employs (a). Yet, if the buyer only consumed one portion of the ticket and sends the other portion for a refund, often he or she will only get back less than half the fare.. Consequently, the firm has actually charged a higher price for the consumed sector ex-post i.e. (d). Furthermore, the firm would have re-sold the unused sector i.e. (b). Curiously, consumers are often grateful to get the refund, without being conscious that they have overpaid for the consumed portion of the service. Finally, buyers facing high valuation risks may not necessarily pay higher for the service when they are able to consume. This is because the higher price may not be exacted on the buyers if sensitivity to valuation risk is high (i.e. (c) in proposition 6 above). Since an increase in demand caused by an offer of refund may compensate for any increase in price, a possibility that was not captured by Png or Xie and Shugan as they modeled the individual consumer (or homogenous consumer segments), but modeled by $\mathrm{Ng}$ [2004].

Ultimately, the optimal price is dependent on demand conditions (e.g. sensitivities and shifting parameters). Nevertheless, this proposition puts forward scenarios that could be modeled or tested empirically by future researchers.

From a theoretical standpoint, revenue management literature often considers the perishability of a service, which of course does not allow the firm to inventory its capacity after production (e.g. Bitran and Caldentey, 2003). Therefore, firms are driven to allocate their capacity optimally across the selling period at optimized prices. In this paper, I show that the inseparability of a service between production and consumption has not yet been explored and yet is of considerable importance. This inseparability does not allow the buyer to keep inventory after purchase and that creates uncertainty in consumption, which in turn, impacts on the buyer's willingness to buy at each point in advance.

\section{THE ABILITY TO PRACTICE REVENUE MANAGEMENT}

Theoretically, the concept of valuation and acquisition risk can be applied to a wide range of services. Since consumer valuation is state dependent at consumption, the various states of consumption could be brought about because of the environment, consumer or firm. Environmental factors such as weather could increase valuation risk for some services, but so would other environmental factors such as the behavior of other customers during consumption. For example, consumers may have a higher valuation risk for a restaurant on weekends because it may be crowded and may lower the perceived benefit of dining there. This, in turn, may deter advanced reservation because buyers may prefer to wait until the day to see how crowded the place is.

Buyer valuation risks may also be brought about by the buyers themselves. As noted earlier, consumers may be struck by illness, be 'not in the mood' or having some other engagement that may reduce the value of consuming a particular service if purchased in advance. Even in auditing services, for example, the client may suddenly take on a new project and would like to change the date of audit. All these serve to push buyers to purchase close to consumption time, so that they become more definite about the value they place on the service.

Valuation risks may also be increased or lowered by the firm. Buyers may not be so eager to buy a service in advance when the firm's reputation (or lack of) may cast a doubt on the ability of the firm to deliver on its promise. In this instance, buyers could prefer to buy at spot.

Finally, the nature of a service may also bring about valuation risk, although in a different form. The service of a divorce attorney is certainly one that is very difficult to purchase in 
advance since a buyer would never know when (if at all) a buyer would require that service. Even if a buyer knows, the service cannot be easily valued because much depends on what is required and on the interactions with the other party. Valuation risk is therefore uncertainty in how a service can be valued, and this uncertainty can arise from the nature of the service, or from environmental, firm or buyer related factors.

Corollary 1: High valuation risks may be attributable to environment, firm, buyer and the nature of the service

In essence, valuation risks result in the inability of the firm to sell the service in advance since consumers are unable to be certain of the value in advance. As a result, from proposition 1 , high valuation risk could reduce advanced demand substantially, resulting in a firm being unable to practice revenue management.

Conversely, proposition 2 demonstrated that acquisition risk drives buyers to buy in advance. Similar to the above, acquisition risk may not be entirely contributed by a firm's limited capacity and perishability of the service. This risk is that of a buyer not being able to attain the perceived benefit of consuming the service. Accordingly, if there is a high degree of substitutability between times of consumption, the perception of acquisition risk could be diminished. Thus, acquisition risk is also driven by four factors. First, environmental conditions e.g. perceived popularity of the service could drive the perception of limited capacity and induce buyers to buy further in advance. Second, the firm itself could place fewer restrictions on the conditions of consumption, allowing the buyer to change the time of consumption and thus reducing the risk of acquisition through the availability of substitutes. Third, the acquisition risk could be imposed and controlled by buyers themselves where a time of consumption is personal to the buyer e.g. an anniversary dinner. Finally, the nature of the service can again contribute to acquisition risk. Some services are incredibly difficult to be substituted at any other times e.g. a tow truck service during a breakdown.

Where there is a high degree of acquisition risk, advanced demand would often exist, allowing many firms to practice revenue management.

Corollary 2a: High Acquisition risks may be attributable to environment, firm, buyer and the nature of the service

Corollary 2b: Services that sell to buyers facing high acquisition risks would be able to practice revenue management

It is important to note that in propounding the issues surrounding valuation and acquisition risks, I have avoided any reference to how prices should be set. This does not mean that pricing is not featured in the analysis. On the contrary, as pricing is demand driven, the common perception of advanced price being lower than spot may not be altogether true. In services where there are more buyers facing low valuation risk and high acquisition risk, it is possible that advanced price is higher than spot, ceteris paribus. For example, a concert that is incredibly popular may price lower closer to spot time when the best seats have been taken.

Furthermore, pricing is dependent on price sensitivity. A firm may find that demand conditions may render it optimal to tradeoff higher prices for greater demand, if its capacity is large. Hence, the traditional view that a firm needs to entice buyers to buy in advance through lower prices may not be an optimal one as the strategic levers to advanced demand lie in how to manage the trade off between the risks perceived by buyers. Without doubt, buyers can still be enticed, but if valuation risks are high, firms may need to lower their advanced prices considerably and this may be more damaging to revenue. The firm could perform better by

Ng, Irene C.L. (2007), "Advanced Demand and a Critical Analysis of Revenue Management", Service Industries Journal, Vol. 27, No. 5 , July 2007 
employing strategies to lower valuation risks instead. Then again, the ability of firms to re-sell would perhaps result in advanced prices being typically lower than spot prices (i.e. proposition 5). What is important is to recognize why that could be so rather than assume advanced discounting as a priori.

\section{REVENUE MANAGEMENT PRACTICES AND TOOLS}

With all that has so far been discussed on the issues within advanced demand, little wonder therefore, that demand seems stochastic, resulting in researchers constructing demand forecasts of greater complexities. This section aims to provide a critique of current revenue management tools by applying the framework presented in $\S 4$.

Kimes [1989, 2003] highlighted various conditions for a firm to be able to practice revenue management. These are relatively fixed capacity, perishable inventory, reservations made in advance, low marginal costs, variable demand and segmentable markets. This was corroborated by Lieberman [1993], Upchurch et al. [2002] and many other researchers. In the context of the framework presented here, it is clear why these conditions are necessary.

Fixed capacity and perishable inventory provides a credible threat towards heightening acquisition risk, resulting in the existence of advanced demand for the practice of revenue management. Yet, some revenue management literature has shown that revenue management could be practiced even when there is not any fixed capacity, or even with high cost of incremental capacity [Weatherford and Bodily, 1992; Weatherford 1997]. As I have presented above, the key towards the practice revenue management is not necessarily fixed capacity, but purchase across a meaningful advanced selling period. Fixed capacity may encourage buyers to buy in advance because of acquisition risk but the threat of non-acquisition (from the consumer's perspective) may also be generated through consumers' inability to afford higher spot prices [Weatherford and Bodily, 1992; Png, 1989; Lee and Ng, 2001]. Consequently, the firm may heighten acquisition risk if it can credibly commit to high spot prices.

Reservations made in advance and variable demand allude to a distribution of demand in advanced of consumption, so that there are variations in prices to manage, and segmentable markets ensure that the firm is able to discriminate on prices. Essentially, as corollary $2 b$ highlighted, it is a firm's ability to sell in advance that allows it to practice revenue management.

Although, this study is consistent with extant literature, I have shown that the conditions of revenue management are symptomatic of the underlying theory why and how advanced demand would exist for the practice of revenue management. By crystallizing the underlying theory, it is worthwhile to consider how revenue management strategies could be developed using the framework presented here.

\section{Overbooking, cancellations and no-shows}

Overbooking, i.e. the accepting of more reservations than one has physical capacity to service as a hedge against cancellations and no-shows, has been claimed as one of the oldest, and from the revenue standpoint, most important of yield management tactics [Karaesmen and van Ryzin, 2004].

Various authors have examined how firms could insure themselves against no-shows or cancellations by consumers, through appropriate reservation policies (e.g. Alstrup et al., 1986; Belobaba, 1989; Hersh and Ladany, 1978; Lieberman and Yechiali, 1978; Rothstein, 1971, 1974, 1985; Thompson, 1961; Toh, 1985). Other researchers, like Pfeifer [1989] have also examined the pricing implications associated with such reservation policies. Research in this area proposes that customers purchase at different times in advance of consumption i.e. some arrive early, and some arrive later (closer to consumption date). The challenge to the firm is how

Ng, Irene C.L. (2007), "Advanced Demand and a Critical Analysis of Revenue Management", Service Industries Journal, Vol. 27, No. 5 , July 2007 
to optimize revenue by pricing and/or setting capacities to be sold at each point in advance, taking into account the arrival times of the customers [Kimes, 1989]. However, it is important to understand the implicit assumptions of this tactic. Without looking at the possibility of re-selling capacity, traditional overbooking assumes that advanced demand is preferred over spot demand (hence the firm overbooks on advanced demand). In other words, when there is a noshow, the traditional view states that it is better to fill the no-show capacity with advanced buyers than to sell it off at spot. This could be for various reasons, most commonly that there is either very little spot demand, that spot prices are uncertain, too low, or that if consumers know that prices could be lower at spot, they will be less willing to buy in advance. Within my analysis here, it is clear that these may not be the case. Within a heterogeneous market, some segments may experience high valuation risk and low acquisition risk, making it possible to create demand at spot, and perhaps extracting higher prices. As pointed out earlier in proposition 6, the firm could sell to inventoried advanced buyers, spot buyers or overbook on advanced buyers.

A further point to be made is not how overbooking should be practiced, as that is surely driven by demand conditions, but also to realize that there is an alternative to overbooking, which is to change demand conditions through service attributes in such a way that there exists a spot demand (buyers that face high valuation risks) to fill the no-show capacity that would not cannibalize advanced sales. To the extent that if spot demand is high and can command superior prices (subject to demand sensitivity), this could potentially drive greater flexibility and lower prices for advanced buyers since no-shows could lead to higher revenue from the reselling of capacity as suggested in propositions 5 and 6.

\section{Demand forecasting}

One of the key principles of revenue management lies in the firm's ability to forecast demand [Jauncey et al., 1995; Pak and Piersma, 2002; Kimes, 1999, 2003]. Revenue management systems must be able to advice on demand conditions by analyzing reservation patterns, arrival, departures and a score of other demand characteristics [Jauncey et al., 1995; Donaghy et al., 1995, 1997]. Recent literature has suggested that revenue management systems with demand forecasting algorithms are increasingly expensive to implement, both in real terms and in lost opportunities [Anderson and Blair, 2004; Desiraju and Shugan, 1999]. A typical system costs between USD\$1 million to \$3 million and takes more than two years to implement [Lahoti, 2002]. Moreover, research has suggested that these complex and sophisticated revenue management systems are not infallible. In fact, with demand forecasts using the data of the past and sales department using present day information, conflicts often occur [ $\mathrm{Ng}$ et al., 1999] and many revenue management systems operate with some level of human intervention, often using these systems as merely a guide.

Demand forecasting may not be very effective for four reasons. First, demand characteristics, upon which revenue management studies are premised, should be based on fundamental concepts of consumer behavior (c.f. Chase, 1999; Lieberman, 1993; Relihan, 1989; Boyd, 2004; Desiraju and Shugan, 1999). Within a historical pattern of demand, why consumers behave the way they do are just as important as how they are behaving. Consequently, as I have indicated earlier in this paper, the past may not be a good indicator of the future, as Cary [2004] has also observed. Second, demand forecasting, at its best, is still an aggregation of multiple segments that could, if possible, be desegregated for higher revenue. Third, past demand profiles are subject to many factors, not least the actions and pricing strategies of the competitors at that time, and the firm's own reaction to them. To assume that demand based on historical data can still hold for the future could be assuming too much. Finally, demand can be influenced, not merely be known. As early as 1951, Schumpeter said that wants cannot be taken as independent and consumers could be taught by producers to

Ng, Irene C.L. (2007), "Advanced Demand and a Critical Analysis of Revenue Management", Service Industries Journal, Vol. 27, No. 5 , July 2007 
want new things [Schumpeter, 1951; Liebhafsky, 1968]. It could, therefore, be more profitable to understand consumer attributes as antecedents of demand. By manipulating acquisition and valuation risks as strategic levers, advanced demand could be influenced and managed for higher revenue. For example, in applying propositions 1, 2 and 3, a service could be modified in such a way that consumers perceive an increase or reduction of valuation and/or acquisition risk. A simple matter of changing a fixed time ticket to allow flexible consumption times immediately lowers valuation risk as buyers can negotiate within themselves to choose the ideal travel time. In the previous example where the business executive was facing high valuation risk by not being certain about which date s/he is to fly, a flexible flight time (e.g. open tickets) might persuade her/him to buy in advance as her/his valuation risk is lowered, thus increasing her/his willingness to pay in advance. Similarly, if there are many flights available for the graduate's father, his acquisition risk is lowered, and he might decide that he does not need to buy in advance.

The analysis presented here accentuates a point. Revenue management tools such as demand forecasting and overbooking to manage uncertainty may not be the only tools on hand to obtain optimal revenue. By assuming that all revenue management, even including the definition of revenue management, must subscribe to these tools, is akin to a potter risking becoming slave to his/her clay. Moreover, using complex demand forecasting techniques and optimization techniques that are based on flawed assumptions may result in a decrease in revenue. As Boyd [2004, page 101] puts it:

...a 'wrong forecasting model' does not refer to the relative merits of linear regression versus exponential smoothing, but to using a method which properly interprets how customers are purchasing so that it can correctly infer future demand from observed data.

It is not the intention of this paper to diminish the role of demand forecasting models. On the contrary, my thesis is to provide a better conceptual understanding of what drives advanced demand so that researchers would see the need to understand the data of the past before inferences can be made about future demand. In addition, links between some of the assumptions of revenue management that some researchers have found could be explained by this framework. For example, Ziya et al. [2004] found no links between decreasing marginal revenue (with respect to demand), decreasing marginal revenue (with respect to price) and increasing price elasticity of demand, commonly observed in revenue functions. The framework presented above could serve as an explanation to the underlying demand behavior. In addition, by understanding the underlying theory, more insights can be generated so that airlines may be able to compete with low fare airlines that strip service attributes down to its bare minimum.

This study aims to offer a theoretical framework towards understanding pricing and revenue management of services in general. Future research can apply the framework into new strategies to manipulate risk levels so that revenue management can be practiced by other service firms. Finally, with the framework and analysis presented, it is hoped that revenue management research can move forward in a more cogent manner. After all, as Yeoman et al. [1999, page 1083] stated, 'the goal of YM is the formulation and profitable alignment of price, product and consumer'.

\section{CONCLUSION}

In formulating this framework, this paper has deliberately avoided mathematical formulations. While mathematical notation is commonly used to illustrate the phenomenon,

Ng, Irene C.L. (2007), "Advanced Demand and a Critical Analysis of Revenue Management", Service Industries Journal, Vol. 27, No. 5 , July 2007 
especially with regard to demand behavior, such notations do not usually reveal implicit assumptions. For example, consumers could be myopic or strategic in their behavior to buy in advance or spot time (c.f. Jagpal, 1999), or be modeled as having strategic interactions with the firm [Png, 1989]. In addition, consumers, in aggregate, could also be price takers in the form of demand functions across time [ $\mathrm{Ng}, 2004]$. Yet, a traditional demand function where consumers are price takers may not completely capture the phenomenon. In the traditional goods view, price taking consumers may be acceptable because it is costly for consumers to gain information. Nowadays, prices and information are far more easily available and consumers are also more strategic.

Moreover, there is currently no mathematical model that completely captures the phenomenon (c.f. Talluri and van Ryzin, 2004). Yet, it is clear that future revenue management should be more demand or customer centric, as highlighted by van Ryzin [2005]. Since this analysis is inter-disciplinary, it aims to advance knowledge in revenue management in a critical manner, through synthesis and analysis, as well as stimulating research interest in as many facets of revenue management as possible. As Kimes [2003] pointed out, revenue management research is divided into three streams: descriptive (application to industry), pricing control (development and improvement of pricing) and inventory control (management of arrivals). Thus, many revenue management researchers may not be conversant with mathematical modeling. In the interest of neither narrowing the audience nor losing the message of the paper, the use mathematics has therefore been avoided. Yet, this does not in any way mean that mathematical models are not useful. On the contrary, advances in revenue management would not have been possible without them. Nevertheless, models often simplify, and findings differ according to how demand is being modeled [Fleishmann et al., 2004], as well as the context within which the model is embedded. By presenting a theoretical framework in this manner, it does not limit how a subset of the phenomenon can be modeled.

This paper presents a theoretical framework of advanced demand through six research propositions. The study presented required a synthesis and analysis of literature from revenue management, pricing, as well as advanced selling models. Such a multi-disciplinary undertaking requires an in-depth understanding of marketing, economics, and operations research in service firms.

The problem with multi-disciplinary papers is that no discipline is extolled and indeed, there is a sense that each discipline could be diminished in its role. The best accountability of a multi and inter-disciplinary paper is towards practice and problem solving. To that end, a major contribution of this paper is its ability to integrate research from the various disciplines to form of a new theoretical framework with the aim of improving both the practice and research of revenue management. Insights from the paper may have far-reaching implications in the way service firms manage and improve their revenues. Instead of traditional revenue management tools, the study proposes how firms can influence advanced demand using the framework as a strategic tool. With the service economy accountable for $79 \%$ of all U.S. jobs and with $74 \%$ of U.S. gross domestic product (GDP) generated by services, service firms are becoming increasingly competitive with revenue management and pricing becoming central in their focus for sustaining long term profitability. As such, insights from this paper would be an invaluable contribution to the future formulation of such strategies.

A remarkable aspect of revenue management research has been its degree of relevance practice. Research in revenue management has been conducted by academics, practitioners and consultants, with a wide range of papers, theoretical and empirical, using an impressive range of methods, quantitative as well as qualitative. Often academic papers are rather esoteric and rather aim for scientific robustness than applicability. In this area, co-operation and multi-method research has truly expanded knowledge. In that spirit, this paper hopes that the analysis

Ng, Irene C.L. (2007), "Advanced Demand and a Critical Analysis of Revenue Management", Service Industries Journal, Vol. 27, No. 5 , July 2007 
presented here provides a cogent framework to move forward in both the practice and research of revenue management.

Ng, Irene C.L. (2007), "Advanced Demand and a Critical Analysis of Revenue Management", Service Industries Journal, Vol. 27, No. 5 , July 2007 
Figure 1: Buyer-Seller Exchange for a Typical Good and a Service

\section{Buyer-Seller Exchange for a Typical Good}

Seller

Line of Perishability

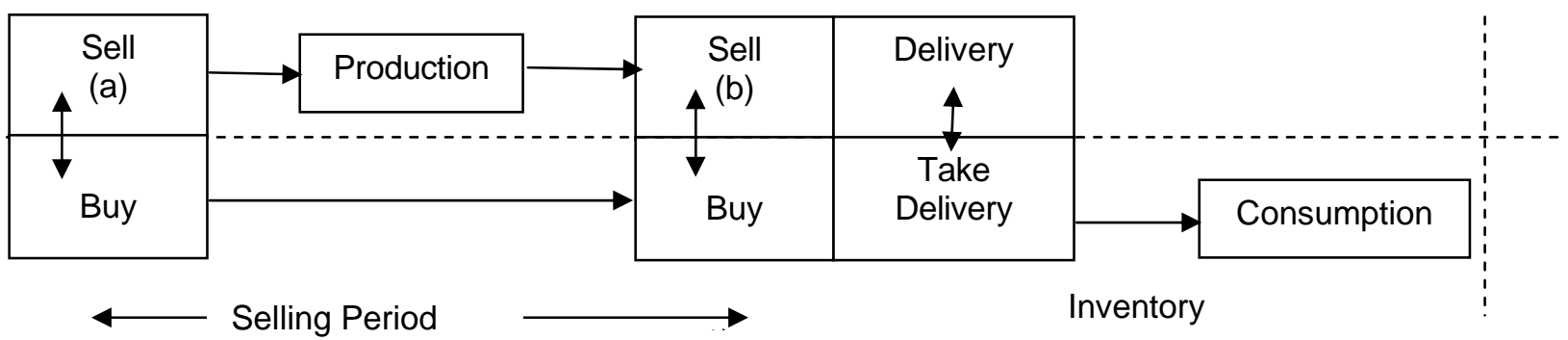

Consumer

Option to

buy/sell at (a)

or (b)

\section{Buyer-Seller Exchange for a Service}

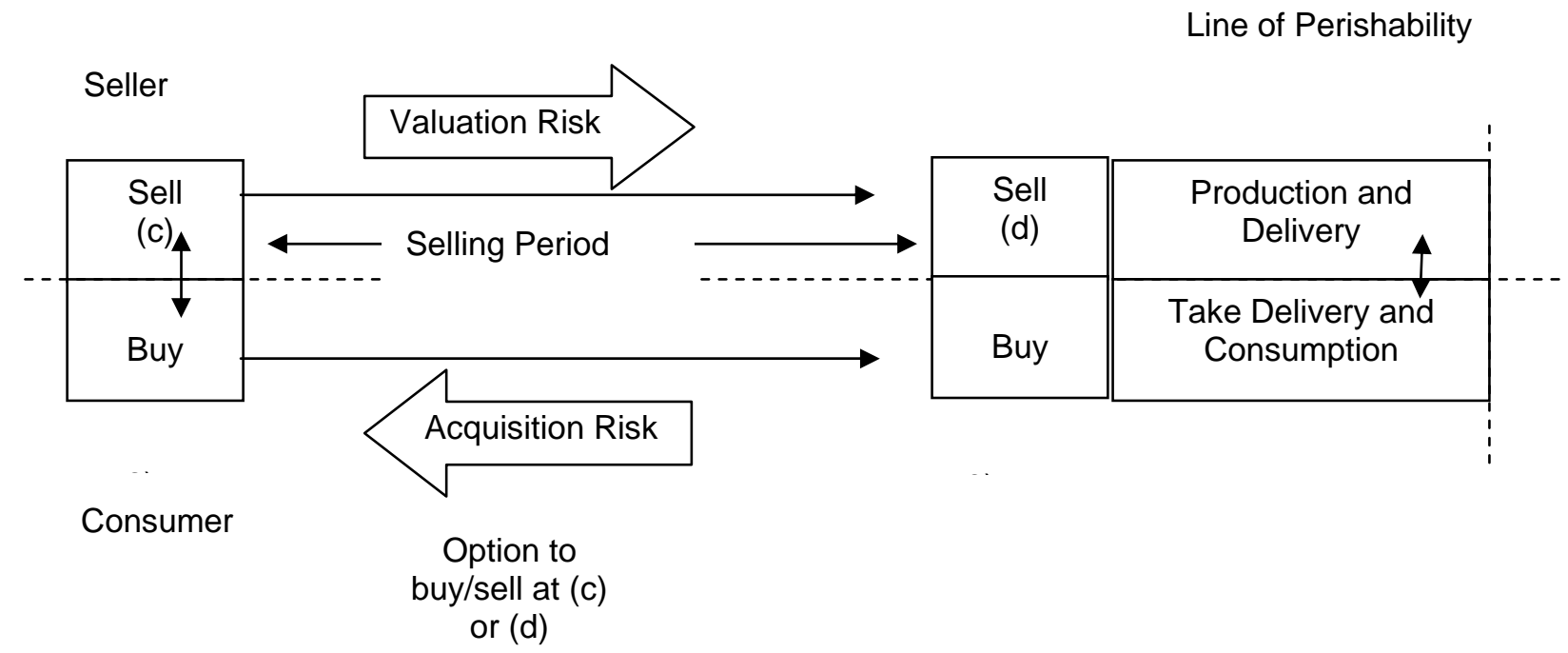

Ng, Irene C.L. (2007), "Advanced Demand and a Critical Analysis of Revenue Management", Service Industries Journal, Vol. 27, No. 5 , July 2007 


\section{Endnotes \\ 'For a glossary of revenue management terms, see McGill and van Ryzin (1999) \\ ii For an overview of revenue management, see Weatherford and Bodily (1992) \\ iii See Bitran and Caldentey (2003) for a review of pricing models in revenue management \\ iv The term 'sale' here technically means 'contracted to buy'. The actual payment could, of course, be after consumption as it is with many services such as professional services.}

Ng, Irene C.L. (2007), "Advanced Demand and a Critical Analysis of Revenue Management", Service Industries Journal, Vol. 27, No. 5, July 2007 


\section{REFERENCES}

Alstrup, J., S. Boas, O. Madsen, and R. Vidal (1986) Booking Policy for Flights with Two Types of Passengers, European Journal of Operations Research, 27, pp. 274-288.

Anderson, C. K., and Blair, M. (2004) Performance Monitor: The Opportunity Costs of Revenue Management, Journal of Revenue and Pricing Management, 2 (4), pp. 353-367.

Bateson, J. (1977) Do We Need Service Marketing. In Pierre Eiglier et al. (eds), Marketing Services: New Insights, Cambridge: Marketing Science Institute.

Belobaba P.P. (1987a) Air Travel Demand and Airline Seat Inventory Management. Doctoral dissertation, Flight Transportation Laboratory, Massachusetts Institute of Technology, Cambridge, MA.

Belobaba P.P. (1987b) Airline Yield Management: An Overview of Seat Inventory Control, Transportation. Science, 21, pp. 63-73.

Belobaba, P. P. (1989) Application of a probabilistic decision model to airline seat inventory control, Operations Research, 37, pp. 183-197.

Bernstein, P. L. (1996) Against the Gods: A Remarkable Story of Risk, New York: John Wiley and Sons.

Bertsimas, D. and Perakis, G. (2001) Dynamic pricing: A learning approach. Working Paper, Operations Research Center, OR 355-01, MIT.

Bitran, G., and Caldentey, R. (2003) An Overview of Pricing Models for Revenue Management, Manufacturing and Service Operations Management, 5(3), pp. 203-229.

Bodily, S. E., and Weatherford, L. R. (1995) Perishable-asset Revenue Management: Generic and Multiple-price Yield Management with Diversion, Omega, International Journal of Management Science, 23 (2), pp. 173-185.

Botimer, T. C., and Belobaba, P. P. (1999) Airline Pricing and Fare Product Differentiation: A New Theoretical Framework, Journal of the Operational Research Society, 50, pp. 10851097.

Boyd, E. A. (2004) Dramatic Changes in Distribution will Require Renewed Focus on Pricing and Revenue Management Models, Journal of Revenue and Pricing Management, 3 (1), pp. 100-103.

Boyd, E. A., and Bilegan, I. (2003) Revenue management and e-commerce, Management Science, 49, pp. 1363-1386.

Carroll, W. J., and Grimes, R. C. (1995) Evolutionary change in product management: Experiences in the car rental industry, Interfaces, 25 (5), pp. 84-104.

Ng, Irene C.L. (2007), "Advanced Demand and a Critical Analysis of Revenue Management", Service Industries Journal, Vol. 27, No. 5 , July 2007 
Cary, D. (2004) A view from the inside, Journal of Revenue and Pricing Management, 3 (2), pp. 200-203(4).

Chase Jr., Charles W. (1999) Revenue Management: A Review, Journal of Business Forecasting Methods and Systems, 18 (2), pp. 2-28.

Cook, P., and Graham, D. A. (1977) The Demand for Insurance and Protection: The Case of Irreplaceable Commodities, Quarterly Journal of Economics, 91, pp. 143-154.

Desiraju, R., and Shugan, Steven M. (1999) Strategic Service Pricing and Yield Management, Journal of Marketing, 63, pp. 44-56.

Dana, J. D. Jr. (1999) Equilibrium Price Dispersion under Demand Uncertainty: The Roles of Costly Capacity and Market Structure, Rand Journal of Economics, 30 (4), pp. 632-660.

Dickson, P. R., and Ginter, J. L. (1987) Market Segmentation, Product Differentiation and Marketing Strategy, Journal of Marketing, 51, pp. 1-10.

Donaghy, K., McMahon, U. and McDowell, D. (1995) Yield Management: An Overview, International Journal of Hospitality Management, 14 (2), pp. 139-150.

Donaghy, K., McMahon, U. and McDowell, D. (1997) Implementing Yield Management : Lesson from the Hotel Sector, International Journal of Contemporary Hospitality Management., 9 (2), pp. 50-54.

Edgett, S., and Parkinson, S. (1993) Marketing for Service Industries - A Review, The Service Industries Journal, 13 (3), pp. 19-39.

Elmaghraby, W., and Keskinocak, P. (2003) Dynamic pricing in the presence of inventory considerations: Research overview, current practices, and future directions, Management Science, 49 (10), pp. 1287- 1309.

Feng, Y. G. Gallego (2000) Perishable asset revenue management with Markovian time dependent demand intensities, Management Science, 46 (7), pp. 941-956.

Fishburn, P. C. (1974) On the Foundations of Decision Making under Uncertainty. In M.Balch, D. McFadden, and S. Wu (eds), Essays on Economic Behavior under Uncertainty, North Holland Publishing Co.

Fleischmann, M., J. M. Hall, and D. F. Pyke (2004) Smart Pricing, MIT Sloan Management Review, 45 (2), pp. 9-13.

Gallego, G., and van Ryzin, G. (1994) A multi-product dynamic pricing problem and its application to network yield management, Operations Research, 45, pp. 24-41.

Gallouj, F. (2002), Innovation in the Service Economy. The New Wealth of Nations, Edward Elgar Publishing.

Ng, Irene C.L. (2007), "Advanced Demand and a Critical Analysis of Revenue Management", Service Industries Journal, Vol. 27, No. 5 , July 2007 
Gorin, T., and Belobaba, P. (2004) Revenue Management Performance in a low fare airline environment: Insights from the Passenger Origin-Destination Simulator, Journal of Revenue and Pricing Management, 3 (3), pp. 215-236.

Hersh, M., and Ladany, S. P. (1978) Optimal Seat Allocation for Flights with One Intermediate Stop, Computers and Operations Research, 5, pp. 31-37.

Jagpal, S. (1999) Marketing Strategy and Uncertainty. Oxford University Press, NY.

Jauncey, S., I. Mitchell, and Slamet, P. (1995) The Meaning and Management of Yield in Hotels, International Journal of Contemporary Hospitality Management, 7 (4), pp. 23-26.

Johnson, E. (1970) The Selling of Services. In Victor P. Buell (eds), Handbook of Modern Marketing, New York: McGraw-Hill.

Jones, P. (1999) Yield Management in UK Hotels: A Systems Analysis, Journal of the Operational Research Society, 50 (11), pp. 1111-1119.

Kannan, P. K., and Kopalle, P. K. (2001) Dynamic Pricing on the Internet: Importance and Implications for Consumer Behavior, International Journal of Electronic Commerce, 5, pp. 63-84.

Karaesmen, I., and van Ryzin, G. (2004) Overbooking with Substitutable Inventory Classess, Operations Research, 52 (1), pp. 83-104.

Karni, E. (1983) Risk Aversion for State-Dependent Utility Functions: Measurement and Applications, International Economic Review, 24 (3), pp. 637-647.

Kimes, S. E. (1989) Yield Management: A Tool for Capacity Constrained Service Firms, Journal Of Operations Mgmt, 8, pp. 348-363.

Kimes, S. E. (1999) Group Forecasting Accuracy in Hotels, Journal of the Operational Research Society, 50, pp. 1104-1110.

Kimes, S. E. (2003) Revenue Management: A Retrospective, Cornell Hotel and Restaurant Administration Quarterly, 30 (3), pp. 14-19.

Kimes, S. E., and Thompson, G. M. (2004), Restaurant Revenue Management at Chevys: Determining the Best Table Mix, Decision Sciences, 35 (3), pp. 371-392.

Kimes, S. E., and Wirtz, J. (2002) Perceived fairness of demand-based pricing for restaurants, Cornell Hotel and Restaurant Administration Quarterly, 41 (1), pp. 338.

Kimes, S. E., and Wirtz, J. (2003) Has revenue management become acceptable? Findings from an international study on the perceived fairness of rate fences, Journal of Service Research, 6 (2), pp. 125-135.

Kuhlmann, R. (2004) Why is Revenue Management not Working? Journal of Revenue and Pricing Management, 2 (4), pp. 378-387.

Ng, Irene C.L. (2007), "Advanced Demand and a Critical Analysis of Revenue Management", Service Industries Journal, Vol. 27, No. 5 , July 2007 
Lahoti, A. (2002) Why CEOs Should Care About Revenue Management: How to minimize the implementation pains and maximize the benefits, OR/MS Today, February, (accessed on 27 May 2005), [available at http://www.lionhrtpub.com/orms/orms-2-02/frrm.html].

Lee, K. S., and Ng., I. C. L. (2001) Advanced Sale of Service Capacities: A Theoretical Analysis of The Impact of Price Sensitivity on Pricing and Capacity Allocations, Journal of Business Research, 54 (3), pp. 219-225.

Lieberman, W. H. (1993) Debunking the Myths of Yield Management, Cornell Hotel and Restaurant Administration Quarterly, 34 (1), pp. 34-41.

Lieberman, V., and Yechiali, U. (1978) On the Hotel Overbooking Problem: An Inventory Problem with Stochastic Cancellations, Management Science, 24, pp. 1117-1126.

Liebhafsky, H. H. (1968) The Nature of Price Theory (Revised Edition). The Dorsey Press, Inc., Homewood.

Littlewood, K. (1972) Forecasting and control of passenger bookings, 1972 AGIFORS Symposia, Alliance Group of the International Federation of Operational Research Scientists, Vol. 12, pp. 95-117.

Lovelock, C., and Wirtz, J. (2003) Services Marketing: People, Technology, Strategy, $5^{\text {th }}$ edition, Prentice Hall.

Martin, B. (1998) The Politics of Research, Information Liberation, London Freedom Press.

McGill, J. I., and van Ryzin, G. J. (1999) Revenue management: Research overview and prospects, Transportation Science, 33, pp. 233-256.

Nair S. K., and Bapna, R. (2001) An Application of Yield Management for Internet Service Providers, with Suresh Nair, Naval Research Logistics, 48 (5), pp. 348-362.

Ng, I. C. L, Wirtz, J., and Lee, K. S. (1999) The Strategic Role of Unused Service Capacity, International Journal Of Service Industry Management, 10 (2), pp. 211-238.

(2004) The Pricing of Services: A Theoretical Framework, Proceedings of the 8th International Research Seminar in Services Management, 4-6 June 2004, La Londe, France.

Pak, K., and Piersma, N. (2002) Overview of OR Techniques for Airline Revenue Management, Statistica Neerlandica, 56 (4), pp. 479-495.

Pfeifer, P. E. (1989) The Airline Discount Fare Allocation Problem, Decision Sciences, 20, pp. 149-157.

Png, I. P. L. (1989) Reservations: Customer Insurance in the Marketing of Capacity, Marketing Science, 8 (3), pp. 248-264.

Ng, Irene C.L. (2007), "Advanced Demand and a Critical Analysis of Revenue Management", Service Industries Journal, Vol. 27, No. 5 , July 2007 
---- (1991) Most-Favored-Customer Protection versus Price Discrimination over Time, Journal of Political Economy, 99 (5), pp. 1010-1028.

Radjou N., Orlov, L. M. and Herbert, L. (2003) Helping Supply Chain Cope with Demand. TechStrategy Report. Forrester Research. Cambridge, Massachusetts.

Rathmell, J. (1966) What is Meant by Services? Journal of Marketing, 30 (4), pp. 32-36.

Regan, W. (1963) The Service Revolution, Journal of Marketing, 27 (3), pp. 57-62.

Relihan III, and Walter, J. (1989) The Yield Management Approach to Hotel-Room Pricing, Cornell Hotel and Restaurant Administration Quarterly, May, pp. 40-45.

Rothstein, M. (1971) An Airline Overbooking Model, Transportation Science, 5, pp. 180-192.

---- (1974) Hotel Overbooking as a Markovian Sequential Decision Process, Decision Sciences, 5, pp. 389-394.

---- (1985), Operations Research and the Airline Overbooking Problem, Operations Research, 33 (2), pp. 237-248.

Schumpeter, J. A. (1951) Economic Theory and Entrepreneurial History. In R. V. Clemence (eds), Essays on Economic Topics of Joseph Schumpeter, Port Washington, NY: Kennikat Press.

Shugan, S.M., and Xie, J. (2000) Advance pricing of services and other implications of separating purchase and consumption, Journal of Service Research, 2 (3), pp. 227-239.

Subramanian, J., Stidham Jr, S. and Lautenbacher, C. J. (1999) Airline Yield Management with Overbooking, Cancellations and No-Shows, Transportation Science, 33 (2), pp. 147-167.

Talluri, K., and van Ryzin, G. (2004) Revenue Management Under a General Discrete Choice Model of Consumer Behavior, Management Science, 50, pp. 15-33.

Thompson, H. R. (1961) Statistical Problems in Airline Reservation Control, Operational Research Quarterly, 12, pp. 167-185.

Toh, R. (1979) Airline Revenue Yield Protection: Joint Reservation Control Over Full and Discount Fare Sales, Transportation Journal, 19 (2), pp. 74-80.

---- (1985) An Inventory Depletion Overbooking Model For the Hotel Industry, Journal of Travel Research, Spring, pp. 24-30.

Upchurch, R. S., Ellis, T. and Seo, J. (2002) Revenue Management underpinnings: An Exploratory Review, Hospitality Management, 21, pp. 67-83.

Van Ryzin, Garrett (2005) Future of Revenue Management: Models of Demand, Journal of Revenue and Pricing Management, 4 (2), pp. 204-209.

Ng, Irene C.L. (2007), "Advanced Demand and a Critical Analysis of Revenue Management", Service Industries Journal, Vol. 27, No. 5 , July 2007 
Weatherford, L. R., and Bodily, S. E. (1992) A Taxonomy and Research Overview of Perishable-Asset Revenue Management: Yield Management, Overbooking, and Pricing, Operations Research, 40, pp. 831-844.

Weatherford, L. R. (1997) Using Prices More Realistically as Decision Variables in perishableAsset Revenue Management Problems, Journal of Combinational Optimization, 1, pp. 277-304.

Williams, L. (1999) Revenue Management: Microeconomics and Business Modeling, Business Economics, 34 (2), pp. 39-45.

Xie, J. and Shugan, S. M. (2001) Electronic Tickets, Smart Cards and Online Prepayments: When and How to Advance Sell, Marketing Science, 20 (3), pp. 219-243.

Yeoman, I., Ingold, A. and Kimes, S. E. (1999) Yield Management: Editorial Introduction, Journal of Operational Research Society, 50, pp. 1083-1084.

Ziya, S., Ayhan, H. and Foley, R. D. (2004) Relationships Among Three Assumptions in Revenue Management, Operations Research, 52 (5), pp. 804-809. 